\section{Vietnam Journal of Agricultural Sciences}

\title{
Production Efficiency Analysis of Indigenous Pig Production in Northwest Vietnam
}

\section{Tran Ba Tuan', Tong Yin², Tran Huu Cuong ${ }^{3}$, Nguyen Cong Tiep $^{4}$ \& Sven König ${ }^{2}$}

\author{
${ }^{1}$ North Vietnam College of Agriculture and Rural Development, Hanoi 134000, Vietnam \\ ${ }^{2}$ Institution of Animal Breeding and Genetics, Justus Liebig University Gießen, Gießen \\ 35390, Germany \\ ${ }^{3}$ Faculty of Accounting and Business Management, Vietnam National University of Agriculture, \\ Hanoi 131000, Vietnam \\ ${ }^{4}$ Faculty of Economics and Rural Development, Vietnam National University of \\ Agriculture, Hanoi 131000, Vietnam
}

\begin{abstract}
This research was conducted to investigate the production efficiency of Ban pig production in northwest Vietnam between October 2016 and January 2017. Primary data obtained from 171 producers were analyzed by applying cost-benefit analysis and stochastic frontier production function. The benefit-cost ratio per litter was 1.24, indicating that the enterprise was profitable. Compared to other farms, the farms focused on farrow-to-finisher attained the highest net return (EUR 213.71/litter), while inputs were used most effectively by the mixed farms. The results from the Cobb-Douglas production function revealed that labour, feeding costs, stocking density, and pigpen structure had positive effects on the production output. Additionally, farms with the phase of farrow-to-nursery obtained less total revenue, while farms focused on the farrow-tofinisher phase achieved higher production outputs than the mixed farms. The level of technical efficiency for each farm ranged between 0.62 and 0.98 , with a mean of 0.88 . The number of live-born piglets and depreciation cost had positive effects, whereas the nursery interval had a negative impact on the technical efficiency. Ban pig producers could increase technical efficiency by efficiently utilizing available resources and improving managerial skills.
\end{abstract}

\section{Keywords}

Stochastic frontier, economic efficiency, indigenous pig, production, North-west Vietnam

\section{Introduction}

The availability of different domesticated animals, e.g., pigs, cows, sheep, and chickens, enriches the household economy because livestock production is a significant element of livelihood strategies for the poorest people in the world (Anderson, 2003). In Vietnam, pig 
production plays a substantial role in livestock husbandry, and pork production accounted for $75.9 \%$ of the total meat production in 2013 (Dzung, 2014). Pigs are well known for their ability to convert different kinds of rough feed, including kitchen waste, to protein (Rahman et al., 2008). Additionally, pigs offer early maturity, a short generation interval, and relatively small space requirements (Ezeibe, 2010). The pig sector is an integral part of mixed farming systems (VAC) in Vietnam as a way to utilize household leftover food and agricultural byproducts. ACIAR-ILRI-CAP (2008) and Hung et al. (2015) reported that the pig sector contributes to about $14 \%$ of the total household income and $25 \%$ of the total household income from agriculture. Pig production is an efficient way to improve protein utilization because, compared to cows, sheep, and goats, pigs grow faster and are more productive (Etim et al., 2014). In northwest Vietnam, one of the main development opportunities for small holders under conditions of increasing land scarcity and environmental degradation is pig production.

Pig production, especially of the indigenous pig (Ban pig), significantly contributes to the economic income, and social and cultural life for most communities in northwest Vietnam. Ban pigs can be readily converted into cash, which helps meet the regular financial demands of the households, such as expenditures for education and spending on basic daily necessities (Hung et al., 2017). As one of the cultural symbols, pork from the Ban pig is also an important food supply at traditional events. Furthermore, manure from pig production is an excellent source of fertilizer to enrich poor soils, and consequently, to improve plant cultivation for farmers. However, the development of Ban pig husbandry is hampered by diseases and lack of village veterinary staff, instability and fluctuations in prices, inadequate technical assistance from extension services, high-fat proportion, low growth rate, low fertility, and poor infrastructure facilities.

Small-scale Ban pig production is a widespread pork production system in northwest Vietnam because of limited resources available to households, e.g., land, labour, and feed produced from agricultural products. Therefore, farmers have to utilize their resources as efficiently as possible. Efficiency is one of the crucial elements influencing productivity growth, especially in agricultural economic development, where resources along with opportunities for developing and adopting technology are limited (Ali \& Chaudhry, 1990).

The term efficiency of a farm can be defined as its ability to provide the largest possible amount of output from a given set of inputs (Palmer and Torgerson, 1999). The stochastic frontier is a helpful tool to approximate production efficiency in agriculture. This model was introduced by Aigner et al. (1977), Meeusen \& van Den Broeck (1977), and Førsund et al. (1980). The principle of this model is based on the concept of the production function, depending on the relationship between the set of inputs and the set of outputs in production. From the classical perspective, producers produce the maximum achievable outputs based on a given technology and level of inputs. This is the definition of the production possibility frontier, which is identified by an optimal relationship between inputs and outputs, and the potentially sub-optimal production activities of the producers are modelled using the concept of technical efficiency. The definition of technical efficiency is the rate of the farm's observed production and the optimal level of production at a given state of inputs and technology. The level of technical efficiency of a farm is identified by the relationship between the detected production and potential production. However, the stochastic frontier model's major weakness is its failure to provide an explicit distribution assumption for the inefficiency term (Sharma et al., 1999).

Over the last few decades, stochastic frontier models have been widely used in agricultural economics studies (Battese \& Coelli, 1995; Ojo, 2003; Abdulai \& Tietje, 2007; Shomo et al., 2010; Adetunji \& Adeyemo, 2012; Belete et al., 2016). Capturing random variables that are beyond the producer's control is the main advantage of this model because the estimation is 
more in accordance with the potential output under "normal" working circumstances (Belete et al., 2016).

Several studies were conducted to investigate productive efficiency in pig farming systems using the stochastic frontier production function, e.g., Etim et al. (2014), Umeh et al. (2015), and Aminu \& Akhigbe-Ahonkhai (2017). However, indigenous pig breeds were not considered in these studies. Hence, it is necessary to analyze the socio-economic factors influencing the economic efficiency of Ban pig production and identify the most efficient source from pig producers in the local farms.

Specifically, the objectives of the present research were (1) to examine the costs and returns from the perspective of local Ban pig farmers; (2) to approximate the level of technical efficiency for Ban pig producers; and (3) to investigate the factors that influence the technical efficiency of Ban pig farms in northwest Vietnam. The findings in this study should be applied in the studied areas to improve the production efficiency of local breeds.

\section{Materials and Methods}

\section{Study area and data collection}

Fieldwork was conducted in three provinces, Son La, Hoa Binh, and Yen Bai, which contain a high density of commercial and local pigs, and are stratified into the three main climatic zones of the Northwest area. One district in each province was selected after consulting with official staff from the Department of Agriculture (Van Ho district - Son La, Tan Lac district - Hoa Binh, and Mu Cang Chai district - Yen Bai). In every district, three communes were chosen purposively based on the following two criteria. First, the study areas were crucial and highintensity regions for Ban pig production. Then, to reduce logistic constraints for data collection, the selected regions were relatively easy to access. Hence, the study areas were Chieng Khoa, Van Ho, Long Luong (Van Ho district); Phu Cuong, Phu Vinh, Dich Giao (Tan Lac district); and Che $\mathrm{Cu}$ Nha, Khao Mang, Pung Luong (Mu Cang Chai district).

The pig farms with at least one sow at the data collecting time were selected. The farms were chosen with the assistance of field extension officers from the Department of Agriculture. Veterinary staff of the communities were also included, especially in offering logistics. Recently, no censuses of Ban pig breeds have been carried out in the study areas. Hence, snowball sampling was used to identify the households that raised local pigs in the communities. This method was used previously in studies of Taenia solium cysticercosis (Sikasunge et al., 2007). The veterinary staff recognized the first few farmers who raised local pigs, and afterwards, other farms were found based on the information from the first farmers.

Single-person interviews with a semistructured questionnaire were conducted for 180 native pig farmers distributed across nine communities in the three divisions from November 2016 to January 2017. The number of farms was 69, 49, and 62 in Van Ho, Tan Lac, and Mu Cang Chai, respectively, and they were approximately in line with the proportion of the total population size of pigs in each area in 2015 (GSO Vietnam, 2016). The main features reflected in the interviews were socio-economic characteristics, management practices, labour use, availability of housing and equipment, capital, and output. A preliminary assessment of 180 questionnaires led to deleting nine respondents because crucial information was missing for those respondents. As a result, 171 farms were kept in the analyses.

\section{Data analysis}

The survey data were analyzed using Stata version 12. The stochastic frontier production function model was applied to estimate the level of technical efficiency and its determinants in Ban pig production. The descriptive statistics of the variables (Table 1), such as means, standard deviations, frequencies, and percentages, were used to interpret the socio-economic 
characteristics of the farmers, as well as the inputs and outputs of the local farms.

\section{Cost-benefit analysis}

The cost-benefit analysis was applied to approximate the farm net revenue for Ban pig production systems. Theoretically, net revenue (NR) is the difference between the total revenue (TR) and the total costs (TC):

$$
\mathrm{NR}=\mathrm{TR}-\mathrm{TC}(1)
$$

Total cost is the accumulation of the entire variable costs (VC) and fixed costs (FC) items:

$$
\mathrm{TC}=\mathrm{VC}+\mathrm{FC}(2)
$$

The variable costs came mainly from the feeding costs, labour costs, and health care costs.

Total revenue was identified as the total amount of money that a producer received from the sale of fattening pigs and piglets:

$$
\mathrm{TR}=\sum \mathrm{P}_{\mathrm{n}} \mathrm{Q}_{\mathrm{n}}(3)
$$

where $\mathrm{P}$ is the price per $1 \mathrm{~kg}$ live weight of the pig $\mathrm{n}^{\text {th }}$ and $\mathrm{Q}$ is the live weight of the pig $\mathrm{n}^{\text {th }}$. The total revenue came mainly from the selling of nursery pigs, finisher pigs, and culled sows.

Gross margin (GM) is the total revenue minus the total variable costs:

$$
\mathrm{GM}=\mathrm{TR}-\mathrm{VC}(4)
$$

The return's ratio was used to calculate the amount of return on an investment relative to the investment costs. It is presented by three formulas:

Rate of returns (RR):

$$
\mathrm{RR}=\mathrm{NR} / \mathrm{TC}(5)
$$

Gross ratio (GR):

$$
\mathrm{GR}=\mathrm{TC} / \mathrm{TR}(6)
$$

Benefit-cost ratio (BCR):

$$
\mathrm{BCR}=\mathrm{TR} / \mathrm{TC}(7)
$$

\section{The stochastic frontier production function}

The general stochastic frontier production function can be defined as:

$$
y_{i}=f\left(x_{i} ; \beta\right) \exp \left(v_{i}-u_{i}\right)(8)
$$

where $y_{i}$ denotes the output of the $i^{\text {th }}$ sample farm $(i=1,2, \ldots n)$; $x_{i}$ is a vector of the inputs used by the $\mathrm{i}^{\text {th }}$ farm; $\beta$ is a vector of the parameters to be estimated; $v_{i}$ represents a random error not under the control of the farmers (measurement error; environment, and diseases, etc.), it follows a normal distribution with $\mathrm{N}\left(0, \sigma_{\mathrm{v}}^{2}\right)$; and $\mathrm{u}_{\mathrm{i}}$ is the one sided-error component that reflects technical inefficiency and is assumed to be independently and identically distributed as a half-normal distribution $\mathrm{N}^{+}\left(0, \sigma_{\mathrm{u}}^{2}\right)$.

The technical efficiency (TE) of the $i^{\text {th }}$ sample farm can be estimated by:

$\mathrm{TE}_{\mathrm{i}}=\frac{\mathrm{y}_{\mathrm{i}}}{\mathrm{y}^{*}}=\frac{\mathrm{F}\left(\mathrm{x}_{\mathrm{i}} ; \beta\right) \exp \left(\mathrm{v}_{\mathrm{i}}-\mathrm{u}_{\mathrm{i}}\right)}{\mathrm{F}\left(\mathrm{x}_{\mathrm{i}} ; \beta\right) \exp \left(\mathrm{v}_{\mathrm{i}}\right)}=\exp \left(-\mathrm{u}_{\mathrm{i}}\right)$

TE ranges from 0 to 1 , indicating the minimum to the maximum level of technical efficiency.

Two functional forms, i.e., log-linear CobbDouglas and Translog production forms, can be applied for the stochastic frontier production function. In this paper, the log-linear CobbDouglas form was adopted. The model was:

$$
\begin{gathered}
\operatorname{lny}=\beta_{0}+\sum \beta_{\mathrm{j}} \ln \mathrm{x}_{\mathrm{ij}}+\beta_{\mathrm{pp}} \text { PPstruct }_{\mathrm{i}}+ \\
\beta_{\mathrm{D}_{1}} \mathrm{D}_{1 \mathrm{i}}+\beta_{\mathrm{D}_{2}} \mathrm{D}_{2 \mathrm{i}}+\left(\mathrm{v}_{\mathrm{i}}-\mathrm{u}_{\mathrm{i}}\right)(10)
\end{gathered}
$$

where $\mathrm{y}_{\mathrm{i}}$ denoted the total revenue of pig production per litter (EUR); $\mathrm{x}_{\mathrm{ij}}$ was the input quantities $\mathrm{j}^{\text {th }}$ used by the $\mathrm{i}^{\text {th }}$ pig farm, including labour (man/days), feeding costs (EUR), health care costs (EUR), and stocking density $\left(\right.$ animal $/ \mathrm{m}^{2}$ ). PPstruct ${ }_{i}$ was the type of pigpen structure (1 for temporary, 2 for semi-permanent, and 3 for permanent); and $D_{1 i}$ and $D_{2 i}$ were dummy variables of operation. For $\mathrm{D}_{1 \mathrm{i}}$, values of 1 were assigned for farms focused on the farrowto-nursery phase, and 0 was given for other farms. For $\mathrm{D}_{2 \mathrm{i}}$, farms with the farrow-to-finishing phase were assigned as 1 , and the other farms received a 0 .

The inefficiency model $\left(\mathrm{u}_{\mathrm{i}}\right)$ was specified as:

$$
\begin{gathered}
\mathrm{u}_{\mathrm{i}}=\delta_{0}+\delta_{1} \text { Age }_{\mathrm{i}}+\delta_{2} \mathrm{Edu}_{\mathrm{i}}+\delta_{3} \text { Dis }_{\mathrm{PL}_{\mathrm{i}}}+ \\
\delta_{4} \text { NurIn }_{\mathrm{i}}+\delta_{5} \text { NumPig_Alive }_{\mathrm{i}}+\delta_{6} \mathrm{CAP}_{\mathrm{i}}+ \\
\delta_{7} \text { Vac_PL }_{\mathrm{i}}(11)
\end{gathered}
$$

where Age was the age of the farmer (in years); Edu was the educational level of the household's head (in school years); Dis_PL was the disease frequency of the pigs (Dis_PL $=1,2$, and 3 for none, low, and high disease frequencies, respectively); NurIn was the nursery interval (in days); Numpig_Alive was the number of live-born piglets (in number); CAP 
was depreciation (in EUR); and Vac_PL was a vaccination for piglets (dummy).

The parameters of the log-linear CobbDouglas and inefficiency model were estimated simultaneously by the maximum likelihood method. The variables used in the model are listed in Table 1.

\section{Results and Discussion}

\section{Costs and returns for pig production}

Table 2 shows the full information in detail about the costs, returns, and profitability of Ban pig production in the research area. The average total cost per litter was EUR 510.99, and the average total revenue was EUR 634.64. The total cost consisted of the variable costs and the fixed costs, in which the average variable cost accounted for $97 \%$, and the fixed cost accounted for $3 \%$. Additionally, the feed costs variable was the most important because it covered the highest proportion of the variable costs of production (78\%), followed by the labour costs of $20 \%$, the health care costs of $1 \%$, and other costs of $1 \%$.

The average gross margin and the net revenue per litter were EUR 139.97 and EUR 123.65 , respectively. The rate of return on investments in Northwest Vietnam was 0.24,

Table 1. Descriptive statistics (standard deviation: SD; minimum: Min; maximum: Max) for revenue, inputs, production management, disease management, type of operation, and socio-economic information

\begin{tabular}{|c|c|c|c|c|c|}
\hline Variable & Unit & Mean & Std. Dev. & Minimum & Maximum \\
\hline Total revenues per litter & EUR & 634.64 & 233.15 & 278.60 & 1382.55 \\
\hline Total net revenue per litter & EUR & 123.65 & 131.11 & -227.82 & 597.96 \\
\hline Labour & Man day & 19.88 & 7.18 & 10 & 50 \\
\hline Feeding costs & EUR & 281.59 & 157.56 & 69.63 & 980.35 \\
\hline Health care costs & EUR & 7.07 & 7.27 & 0.00 & 39.80 \\
\hline Stock density & Pigs $/ \mathrm{m}^{2}$ & 1.28 & 0.68 & 0.29 & 3.00 \\
\hline Pigpen structure & & 2.51 & 0.77 & 1.00 & 3.00 \\
\hline Farm location & & 1.95 & 0.85 & 1.00 & 3.00 \\
\hline Age & Years & 41.02 & 10.11 & 24.00 & 65.00 \\
\hline Educational level & School years & 5.72 & 4.09 & 0.00 & 12.00 \\
\hline Nursery interval & Days & 138.13 & 40.28 & 60.00 & 240.00 \\
\hline Number of live-born piglets & Number & 7.47 & 1.10 & 5.20 & 10.60 \\
\hline Depreciation & EUR & 16.32 & 12.72 & 0.84 & 82.11 \\
\hline Disease frequency of pigs & Times & 2.18 & 0.76 & 1.00 & 3.00 \\
\hline Vaccination for piglets & & 0.28 & 0.45 & 0.00 & 1.00 \\
\hline Vaccination for sows & & 0.46 & 0.50 & 0.00 & 1.00 \\
\hline Farrow-to-nursery operation & & 0.62 & 0.49 & 0.00 & 1.00 \\
\hline Farrow-to-finisher operation & & 0.16 & 0.37 & 0.00 & 1.00 \\
\hline
\end{tabular}


Table 2. Average costs, returns, and profitability of Ban pig production in EUR/Litter

\begin{tabular}{|c|c|c|}
\hline Variable & Amount (EUR) & $\%$ of TC \\
\hline Total revenues (TR) & 634.64 & \\
\hline Variable costs (VC) & 494.67 & 0.97 \\
\hline - Feed & 383.32 & 0.78 \\
\hline - Labour & 99.46 & 0.20 \\
\hline - Medication & 7.07 & 0.01 \\
\hline - Other costs & 4.82 & 0.01 \\
\hline Fixed costs (FC) & 16.32 & 0.03 \\
\hline Total costs (TC) & 510.99 & \\
\hline Gross margin (GM) & 139.97 & \\
\hline Net revenues (NR) & 123.65 & \\
\hline Return rate (RR) & 0.24 & \\
\hline Benefit-cost ratio (BCR) & 1.24 & \\
\hline Gross ratio (GR) & 0.81 & \\
\hline
\end{tabular}

indicating that for every EUR 1 invested, EUR 0.24 was gained from pig production as a profit. This result is lower than that of studies on pig production in Ekiti State (Aminu \& AkhigbeAhonkhai 2017) and Oyo State (Adetunji \& Adeyemo 2012), where the rates of return on investments were 0.34 and 0.82 , respectively. The benefit-cost ratio of 1.24 depicted that Ban pig production was a profitable business in northwest Vietnam as it was greater than one. The gross ratio was 0.81 , implying that EUR 0.81 was spent for every EUR 1 return in the production.

The differences in costs, returns, and profitability of pig production for farms among three types of operations are presented in Table 3 . The farms focused on the phase of farrow-tofinish achieved the highest profit of EUR 213.71 per litter, while the profit decreased to EUR 75.46 per litter if farms only concentrated on the phase of farrow-to-nursery. However, the rate of return in the farms that mixed both phases $(0.35)$ was higher than the farms only undertaking one phase, i.e., farrow-to-finish (0.28) or farrow-tonursery $(0.17)$. Also, the gross ratios of the three types of farms were $0.74,0.78$, and 0.85 , suggesting that for every EUR 1 return from the pig production system, EUR 0.74, EUR 0.78, and EUR 0.85 were spent by the farmers in the mixed, farrow-to-finish, and farrow-to-nursery farms, respectively. This implies that pig producers from mixed farms used inputs more efficiently than others.

\section{Parameters of the production factors}

Parameters estimated from the stochastic frontier production function are presented in Table 4. The results revealed that the coefficients of most of the inputs were statistically significant at different levels, except for the health care costs. The coefficient of labour was positive with a value of 0.07 , which was significant at $10 \%$. This means that a $1 \%$ increase in the man-day increased the total revenue by $0.07 \%$ when other factors were kept constant. This finding is in line with research on the profitability and technical efficiency of pig production in Ekiti State (Aminu and Akhigbe-Ahonkhai, 2017), and the study on efficiency in small-scale pig production in Akwa Ibom State (Etim et al., 2014). The 
Table 3. Average costs, returns, and profitability of Ban pig production in EUR/Litter in farms focused on the phases of farrow-tonursery, farrow-to-finish, or a mixture of both

\begin{tabular}{|c|c|c|c|}
\hline Variable & Farrow-to-nursery & Farrow-to-finish & Mixed farm \\
\hline Total revenues (TR) & 488.64 & 986.13 & 786.91 \\
\hline Variable costs (VC) & 403.18 & 753.11 & 561.20 \\
\hline - Feed costs & 301.30 & 619.09 & 439.88 \\
\hline - Labour costs & 90.15 & 121.36 & 109.56 \\
\hline - Medication costs & 7.06 & 7.35 & 6.89 \\
\hline - Other costs & 4.67 & 5.31 & 4.87 \\
\hline Fixed costs (FC) & 13.80 & 19.32 & 21.25 \\
\hline Total costs TC & 416.98 & 772.43 & 582.45 \\
\hline Gross margin (GM) & 85.46 & 233.03 & 225.71 \\
\hline Net revenues (NR) & 71.66 & 213.71 & 204.47 \\
\hline Return rate (RR) & 0.17 & 0.28 & 0.35 \\
\hline Benefit-cost ratio (BCR) & 1.17 & 1.28 & 1.35 \\
\hline Gross ratio (GR) & 0.85 & 0.78 & 0.74 \\
\hline
\end{tabular}

coefficient of the feeding cost was 0.27 , which was significant at $1 \%$, indicating that every $1 \%$ increase in the feeding cost raised the total return by $0.27 \%$. The large elasticity of feed costs is an indicator of the importance of concentrates in pig production. These results conform to prior studies by Adetunji \& Adeyemo (2012) and Etim et al. (2014). The health care costs had a negative coefficient but was not significant, even at the $10 \%$ level.

The elasticity of the stocking density was 0.03 and positively significant at the $10 \%$ level, suggesting that a $1 \%$ increase in the stocking density increased output by $0.03 \%$. In contrast, a significant negative coefficient of the stocking density was reported in pig production in Akwa Ibom State (Etim et al., 2014). The positive value of the stocking density coefficient in this study suggested that increasing the stock of animals tended to increase the timeliness of resources used, as a result leading to an increase in technical efficiency.

Additionally, the type of pigpen and operation had significant impacts on the total revenue of pig production. The production elasticity concerning the pigpen style was positive with a value of 0.04 and significant at $5 \%$, indicating that the better the pigsty conditions, the higher revenue farmers earned from pig production. The coefficient of farms with the phase farrow-to-nursery was negative, while farms focused on the farrow-to-finisher phase had a positive coefficient, and both were significant at the $1 \%$ level. The elasticity of -0.30 implied that the farrow-to-nursery farms tended to get $0.30 \%$ less in total revenue than the mixed farms. In contrast, higher output $(0.10 \%)$ were achieved for farms with farrow-to-finisher compared with the mixed farms.

\section{Determinants of technical efficiency in Ban pig production}

The estimated coefficients of the inefficiency model are listed in Table 4. The coefficient of the nursery interval $(0.01)$ was positive and significant at the 5\% level, suggesting that technical inefficiency effects increased with an increase in the nursery interval. 
Table 4. Coefficient, standard error, and Z-value of parameters estimated from the stochastic frontier production function for Ban pig production

\begin{tabular}{|c|c|c|c|c|}
\hline Variable & Parameter & Coefficient & Standard error & $Z$ value \\
\hline \multicolumn{5}{|l|}{ Production function } \\
\hline Constant term & $\beta_{0}$ & $4.91^{* \star *}$ & 0.21 & 23.03 \\
\hline Labour & $\beta_{1}$ & $0.07^{*}$ & 0.04 & 1.78 \\
\hline Feeding costs & $\beta_{2}$ & $0.27^{* \star *}$ & 0.03 & 8.35 \\
\hline Health care costs & $\beta_{3}$ & $-0.002^{\mathrm{ns}}$ & 0.003 & -0.77 \\
\hline Stock density & $\beta_{4}$ & $0.03^{*}$ & 0.02 & 1.66 \\
\hline Pigpen structure & $\beta_{\mathrm{pp}}$ & $0.04^{* *}$ & 0.02 & 2.09 \\
\hline Farrow-to-nursery & $\beta_{\mathrm{D} 1}$ & $-0.30^{* * *}$ & 0.03 & -8.64 \\
\hline Farrow-to-finisher & $\beta_{\mathrm{D} 2}$ & $0.10^{* * *}$ & 0.04 & 2.73 \\
\hline \multicolumn{5}{|l|}{ Inefficiency model } \\
\hline Constant term & $\delta_{0}$ & $1.06^{\mathrm{ns}}$ & 1.69 & 0.63 \\
\hline Age & $\delta_{1}$ & $0.004^{\text {ns }}$ & 0.02 & 0.20 \\
\hline Education level & $\delta_{2}$ & $0.001^{\mathrm{ns}}$ & 0.05 & 0.01 \\
\hline Disease frequency of piglets & $\delta_{3}$ & $0.02^{\mathrm{ns}}$ & 0.25 & 0.08 \\
\hline Nursery interval & $\delta_{4}$ & $0.01^{* *}$ & 0.05 & 2.21 \\
\hline Number of live-born piglets & $\delta_{5}$ & $-0.78^{*+*}$ & 0.2 & -3.96 \\
\hline Depreciation cost & $\delta_{6}$ & $-0.04^{* *}$ & 0.02 & -1.99 \\
\hline Vaccination for piglets & $\delta_{7}$ & $-0.47^{\mathrm{ns}}$ & 0.43 & -1.10 \\
\hline Log-likelihood function & & 86.20 & & \\
\hline
\end{tabular}

Note: ${ }^{*},{ }^{* *}$, and ${ }^{* * *}$ show statistical significance levels at $10 \%, 5 \%$, and $1 \%$, respectively; ns: no statistical significance.

Hence, every one-day increase in the nursery interval declined output by $0.01 \%$ in Ban pig production. The results also revealed that technical inefficiency was reduced with an increase in the number of live-born piglets per litter. This suggests that the farms that had a higher number of live-born piglets per litter achieved a higher level of technical efficiency. The variable depreciation had a coefficient of 0.04 and was significant at the 5\% level, indicating that technical efficiency rose with an increase in the expenditures for housing and equipment in pig production. Consequently, this points to the importance of investments in accommodations in Ban pig production. Interestingly, the coefficient of age and education level of the household's head in this research was not statistically significant even at the $10 \%$ level as reported in the previous studies by Adetunji \& Adeyemo (2012), and Aminu \& Akhigbe-Ahonkhai (2017).

\section{Distribution of respondents by technical efficiency}

The specific level of technical efficiency for pig producers obtained from the stochastic 
frontier model is presented in Table 5 . Substantial differences in technical efficiency scores among Ban pig producers were identified. The predicted levels of technical efficiency for each farm ranged from 0.62 to 0.98 , with a mean of 0.88 , which agreed with the previous findings by Aminu \& Akhigbe-Ahonkhai (2017) but were lower than the estimations by Etim et al. (2014) and Umeh et al. (2015). Two-thirds of the farms (78\%) operated at levels of technical efficiency below 0.95 , while $22 \%$ of the pig producers achieved levels of technical efficiency from 0.95 to 0.98 . This indicated that none of the pig farms could produce on the frontier of the pig production function. In contrast, Ly et al. (2016) reported that $8 \%$ of households were fully efficient.

The average technical efficiency of pig breeders was 0.88 , suggesting that the Ban pig farmers in northwest Vietnam were producing at $88 \%$ of their potential production levels. Therefore, on average, the level of technical efficiency could be increased by $12 \%$ for the Ban pig producers through efficiently utilizing available resources with the current state of technology. The least efficient producer could save costs by $35 \%$ (1-63/98) if production could be as efficient as the farm with the maximum technical efficiency.

\section{Conclusions}

The profitability and technical efficiency of Ban pig production in northwest Vietnam were estimated using the cost-benefit analysis and the stochastic frontier production function. Inputs were utilized the most effectively by the mixed farms, while farms focused on the farrow-tofinisher phase attained the highest net returns. The production inputs, e.g., feeding costs, labour, stocking density, and pigpen style, contributed positively to the output from the Ban pig production. Farms focused on the farrow-tofinisher phase achieved the highest economic efficiency, while the farms with the farrow-tonursery phase had the lowest economic efficiency.

The main factors that affected technical efficiency in indigenous pig enterprises were nursery interval, number of live-born piglets, and the investments in housing and equipment. The findings of the present study revealed that all of the pig farms operated below the frontier threshold. The results showed that on average, the technical efficiency of Ban pig producers could be raised by $12 \%$ through improving managerial skills, housing, and equipment for pig production. Therefore, the local extension organizations should provide training courses on pig production management for the breeders to increase technical efficiency.

Table 5. Efficiency distribution of the Ban pig producers

\begin{tabular}{|c|c|c|c|}
\hline Technical efficiency level & & Frequency & Percentage \\
\hline $0.62-0.80$ & & 30 & 17 \\
\hline $0.81-0.90$ & & 60 & 35 \\
\hline $0.91-0.94$ & & 44 & 26 \\
\hline $0.95-0.98$ & & 37 & 22 \\
\hline Minimum efficiency & 0.62 & & \\
\hline Maximum efficiency & 0.98 & & \\
\hline Mean efficiency & 0.88 & & \\
\hline
\end{tabular}




\section{Acknowledgments}

We are thankful for the communities in the research areas in Van Ho district (Son La), Tan Lac district (Hoa Binh), and Mu Cang Chai district (Yen Bai) for sharing their knowledge on their pig farming and allowing us to work with them.

\section{References}

Abdulai A. \& Tietje H. (2007). Estimating technical efficiency under unobserved heterogeneity with stochastic frontier models: application to northern German dairy farms. Eurpean Review of Agricultural Economics. 34: 393-416.

ACIAR-ILRI-CAP (2008). Market actor survey. Hanoi.

Adetunji M. \& Adeyemo K. (2012). Economic efficiency of pig production in Oyo State, Nigeria: a stochastic production frontier approach. American Journal of Experimental Agriculture. 2: 382.

Aigner D., Lovell C. K. \& Schmidt P. (1977). Formulation and estimation of stochastic frontier production function models. Journal of Econometrics. 6: 21-37.

Ali M. \& Chaudhry M. A. (1990). Inter-regional farm efficiency in Pakistan's Punjab: a frontier Production function study. Journal of Agricultural Economics. 41: 62-74.

Aminu F. O. \& Akhigbe-Ahonkhai C. E. (2017). Profitability and Technical Efficiency of Pig Production in Nigeria: the Case of Ekiti State. Agricultura Tropica et Subtropica. 50: 27-35.

Anderson S. (2003). Animal genetic resources and sustainable livelihoods. Ecological economics. 45: 331-339.

Battese G. E. \& Coelli T. J. (1995). A model for technical inefficiency effects in a stochastic frontier production function for panel data. Empirical economics. 20: 325332.

Belete A., Setumo M., Laurie S. \& Senyolo M. (2016). A Stochastic Frontier Approach to Technical Efficiency and Marketing of Orange Fleshed Sweet Potato (OFSP) at Farm Level: A Case Study of KwazuluNatal Province, South Africa. Journal of Human Ecology. 53: 257-265.

Dzung N. M. (2014). Pig production and marketing in Vietnam. Country report. 145-152.

Etim N., Etim N. \& Offiong E. E. (2014). Estimation of efficiency in small scale pig production. EURpean International Journal of Science and Technology. 3: 111-118.

Ezeibe A. (2010). Profitability analysis of pig production under intensive management system in Nsukka Local Government Area of Enugu State, Nigeria. International Journal of Economic Development
Research and Investment. 1: 48-54.

Førsund F. R., Lovell C. K. \& Schmidt P. (1980). A survey of frontier production functions and of their relationship to efficiency measurement. Journal of Econometrics. 13: 5-25.

GSO (General Statistical Office) (2016). Statistical Yearbook Vietnam 2015. Statistical Publishing House, Hanoi, Vietnam.

Hung P. V., Nga N. T. D. \& Lapar L. (2015). Improving the livelihood of small farmers in the pig value chain: Experiences in the north of Vietnam. Regional seminar on "Agriculture Development for the Mekong Delta: How to Increase the Livelihood of Farmers", Can Tho City, Vietnam, April 24, 2015. Hanoi, Vietnam: Vietnam National University of Agriculture.

Hung P. V., Nga N. T. D. \& Lapar L. (2017). Pig production and farm income in the pig value chain in Hung Yen and Nghe An provinces. Vietnam Journal of Agricultural Science. 15(9): 1301-1308.

Ly N. T., Nanseki T. \& Chomei Y. (2016). Technical Efficiency and Its Determinants in Household Pig Production in Vietnam: A DEA Approach. The Japanese Journal of Rural Economics. 18: 56-61.

Meeusen W. \& van Den Broeck J. (1977). Efficiency estimation from Cobb-Douglas production functions with composed error. International Economic Review. 18(2): 435-444.

Ojo S. (2003). Productivity and technical efficiency of poultry egg production in Nigeria. International Journal of Poultry Science. 2: 459-464.

Palmer S. \& Torgerson D. (1999). Economic Notes: Definitions of Efficiency. BMJ Clinical Research. 318(7191): 1136. DOI: 10.1136/bmj.318.7191.1136.

Rahman S., Barthakur S. \& Kalita G. (2008). Pig production and management system in Aizawl district of Mizoram, India. Livestock Research for Rural Development 20 (9)

Sharma K. R., Leung P. S. \& Zaleski, H. M. (1999). Technicalities allocative and economic efficiencies in swine production in Hawaii. A comparison of parametric and non parametric approaches. Agricultural Economics. 20:23-35.

Shomo F., Ahmed M., Shideed K., Aw-Hassan A. \& Erkan O. (2010). Sources of technical efficiency of sheep production systems in dry areas in Syria. Small Ruminant Research. 91: 160-169.

Sikasunge C., Phiri I., Phiri A., Dorny P., Siziya S. \& Willingham A. L. (2007). Risk factors associated with porcine cysticercosis in selected districts of Eastern and Southern provinces of Zambia. Veterinary Parasitology. 143: 59-66.

Umeh J. C., Ogbanje C. \& Adejo M. (2015). Technical efficiency analysis of pig production: A sustainable animal protein augmentation for Nigerians. Journal of Advanced Agricultural Technologies. 2(1). DOI: 10.12720/joaat.2.1.19-24. 